\title{
Developing selection criteria based on an ontogenetic path analysis approach to improve grain yield in barley
}

\author{
T.A. Setotaw ${ }^{1,2}$, S.G. Belayneh ${ }^{1}$, R. Gwinner ${ }^{3}$ and J.L. Ferreira ${ }^{4,5}$ \\ ${ }^{1}$ Kulumsa Agricultural Research Center, Assela, Ethiopia \\ ${ }^{2}$ Laboratório de Biotecnologia Vegetal, \\ Empresa de Pesquisa Agropecuária de Minas Gerais, Caldas, MG, Brasil \\ ${ }^{3}$ Setor de Grandes Culturas, Departamento de Agricultura, \\ Universidade Federal de Lavras, Lavras, MG, Brasil \\ ${ }^{4}$ Empresa Brasileira de Pesquisa Agropecuária, Embrapa Pecuária Sul, \\ Bagé, RS, Brasil \\ ${ }^{5}$ Centro de Ciências Agrárias, Universidade da Região da Campanha, \\ Bagé, RS, Brasil \\ Corresponding author: T.A. Setotaw \\ E-mail: setotaw2006@gmail.com
}

Genet. Mol. Res. 13 (2): 4635-4646 (2014)

Received June 14, 2013

Accepted December 3, 2013

Published June 18, 2014

DOI http://dx.doi.org/10.4238/2014.June.18.6

ABSTRACT. We used correlation and path coefficient analysis based
on an ontogenetic approach to develop selection criteria in barley
(Hordeum vulgare L.) for an early production system in Ethiopia. A total
of 100 genotypes using $10 \mathrm{x} 10$-simple lattices with two replications
were used to perform the experiment at Ambo and Asasa. The combined
analysis of the measured traits showed significant differences among
genotypes for all traits. A positive correlation was observed between
grain yield and spike $/ \mathrm{m}^{2}$, kernel number $/ \mathrm{spike,} \mathrm{and} 1000-\mathrm{kernel}$ weight.
The path analysis showed that spike $/ \mathrm{m}^{2}, 1000-$ kernel weight, and
kernel number per spike had significant positive direct effects on grain
yield, which shows that these traits can be used as selection criteria 
to improve grain yield. The significant positive correlation of spike/ $\mathrm{m}^{2}, 1000$-kernel weight, and grain-filling period and the positive direct effect on grain yield indicated the potential of these traits as indirect selection criteria to improve grain yield in the early production system in Ethiopia. This study also showed that the path coefficient analysis based on an ontogenetic model was efficient and produced results that can be interpreted clearly.

Key words: Path coefficient analysis; Correlation analysis; Hordeum vulgare L.; Ontogenetic plant development; Belg production system; Early production system

\section{INTRODUCTION}

Barley (Hordeum vulgare L.) is one of the most important cereal crops in Ethiopia and is used as malt and food. Barley is grown from low land (1500 $\mathrm{m}$ above sea level) to high land (3000 m above sea level) regions of Ethiopia (Lakew et al., 1996). Barley is also one of the principal cereal crops in the mid altitude and early production system of the country (Abay and Bjørnstad, 2009). Most of the farmers in these areas use their own landrace because of the absence of barley cultivars released from research institutes.

The objective of barley breeders in these areas is to develop barley cultivars that are well-adapted, high yielding, and suit the early production system of the region that is frequently affected by terminal moisture stress. To develop cultivars that are suitable for these areas, it is important to design appropriate selection criteria that can increase the efficiency of selection in the target environment. Smith et al. (1990) and Ceccarelli and Grando (1991) showed the importance of selecting genotypes in the target environment if the objective is to develop cultivars for a stress environment. Developing an efficient selection method required the study of yield component associations and their influence on grain yield. At this point, correlation and path coefficient analysis can be used to understand the inter-relationships among yield components and the direct and indirect effects of yield components on grain yield.

The importance of the correlation coefficient in designing an effective breeding strategy was presented by Johnson et al. (1955) and Ariyo et al. (1987). The correlation coefficient analysis among yield components and grain yield was used to develop selection criteria for barley (Mandal and Dana, 1993; El-Hennawy, 1997; Sajeda et al., 1997; Shami et al., 1997).

However, the number of independent variables affecting the dependent variable increased, the correlation coefficient alone cannot explain the direct and indirect effects of each component on the dependent variable (yield) (Bhatt, 1973). However, path analysis, which was first presented by Wright (1934) and elaborated by Li (1976), can be employed and was used by different authors to develop selection criteria in different crops; this method proved to be efficient in determining the direct and indirect effects of the independent variable on the dependent variable. Dewey and Lu (1959) used correlation and path analysis to develop selection criteria that considered bidirectional relationships among yield components without considering the ontogenetic plant development. Based on this assumption, Mandal and Dana (1993), El-Hennawy (1997), Sajeda et al. (1997), Naik et al. (1998), and Singh et al. (1998) used path analysis in barley. The use of bidirectional 
relationships among yield components has some drawbacks because it does not consider the ontogenetic plant development concept that the trait that develops in the later stage of plant development cannot affect the trait that develops earlier.

Recently, an alternative method of path analysis has been used frequently to determine the different levels of paths in a path analysis model that uses a sequential stepwise regression method. In this method, the order of the independent variables that affect the dependent variable was determined based on the percentage of variability that was explained by the independent variables without considering the ontogenetic plant development as presented by Zadoks et al. (1974) and the cause and effect relationships among traits (Wright, 1934; Li, 1976; Kozak and Azevedo, 2011). In this method, the independent variable explains more variability in the dependent variable that is considered as the first order, the variable that explains less variability is considered as the last-order variable. This method only considers the statistical property of the method and does not consider the stage of plant development or the biological aspect of plant development. The drawback of using a sequential stepwise regression model for variable selection to build the sequential path analysis model was explained in detail by Kozak and Azevedo (2011).

Mohammadi et al. (2003) and Maleki et al. (2011) used sequential regression to define the path analysis model that contradicted the basic assumption of path analysis, which is only used to test the fit of the assumed model and not to produce it (Wright, 1934; Li, 1976). Li (1976) emphasized the requirement of determining the cause and effect relationships among variables based on prior evidence to employ path analysis, and this cannot be used to generate a hypothesis.

This showed the importance of developing cause and effect relationships among yield components to employ path analysis. Therefore, the path analysis model considering the sequential ontogenetic plant development of yield components meets this objective and shows the cause and effect relationship among yield components (Zadoks et al., 1974). Based on this assumption, Dofing and Knight (1992) compared the bidirectional association of yield components (Dewey and Lu, 1959) and the sequential ontogenetic plant development (Zadoks et al., 1974) approach to select the best model that explains the relationship; they concluded that the sequential ontogenetic approach better explained the path analysis model. In this study, they found that spike $/ \mathrm{m}^{2}$, kernel weight, and kernel number/spike had positive direct effects on grain yield and can be used as selection criteria in the breeding of spring barley. Deniz et al. (2009) also used ontogenetic path coefficient analysis to determine the direct and indirect effect of yield components on grain yield in spring barley. Similarly, García del Moral et al. (2003) used ontogenetic-based path analysis in wheat to identify the appropriate selection criteria in Spain.

Based on our knowledge, this type of information is not available in barley in Ethiopia, especially in the early production system of the country. This shows the importance of developing appropriate selection criteria using an ontogenetic path analysis model for this crop in the early production system to improve the selection efficiency and consequently increase productivity. The lack of this information will hinder the efficiency of developing genotypes that are well adapted to the specific environment, which suffers from terminal moisture stress.

Therefore, the objective of this study is to develop selection criteria based on sequential ontogenetic path coefficient analysis in barley (H. vulgare L.) to improve grain yield in the early production system of the country. 


\section{MATERIAL AND METHODS}

\section{Plant materials}

One hundred barley genotypes [65 from the International Center for Agricultural Research in the Dry Areas (ICARDA) barley-breeding program and 35 landrace lines developed by the National Barley Improvement program of the country] that were developed for midaltitude and low-moisture areas were evaluated in this study.

\section{Experimental design and test locations}

The 100 genotypes described above were planted in two locations, Asasa and Ambo, which represent the mid-altitude areas of the country in the 2000-2001 crop season. Asasa lies at $7^{\circ} 7^{\prime} \mathrm{N}, 39^{\circ} 11^{\prime} \mathrm{E}$ and is located at an altitude of $2300 \mathrm{~m}$ above sea level. The long-term annual rainfall mean is $600 \mathrm{~mm}$. The annual minimum and maximum temperature is 5.4 and $24^{\circ} \mathrm{C}$, respectively. The Ambo Plant Protection Research Center lies at $08^{\circ} 57^{\prime} \mathrm{N}, 38^{\circ} 7^{\prime} \mathrm{E}$ and is located at an altitude of $2200 \mathrm{~m}$ above sea level. The long-term annual rainfall mean is $740 \mathrm{~mm}$. The long-term annual maximum and minimum temperature is 25.6 and $10.3^{\circ} \mathrm{C}$, respectively. The experiment had a $10 \times 10$-simple lattice design with two replications and a plot size of $1.2 \mathrm{x}$ $2.5 \mathrm{~m}$ with $20 \mathrm{~cm}$ between rows. The grain yield $/ \mathrm{m}^{2}$ and yield component measurements were taken from the four central rows of each plot. Seed and fertilizer rates were used as recommended for the experimental sites. At Asasa, $18 \mathrm{~kg} / \mathrm{ha} \mathrm{N}$ and $46 \mathrm{~kg} / \mathrm{ha} \mathrm{P}_{2} \mathrm{O}_{5}$ were applied, while at Ambo, $20 \mathrm{~kg} / \mathrm{ha} \mathrm{N}$ and $55 \mathrm{~kg} / \mathrm{ha} \mathrm{P}_{2} \mathrm{O}_{5}$ were applied during planting. The seed rate used was $85 \mathrm{~kg} / \mathrm{ha}$.

\section{Data collection}

Data on plant height, number of tillers/plant, number of spikes $/ \mathrm{m}^{2}$, number of spikelets/spike, and number of kernels/spike were recorded from 10 randomly taken plants from each plot, and the average values were used for subsequent statistical analysis. Days to heading, days to maturity, 1000-kernel weight (TKW), and grain yield $/ \mathrm{m}^{2}$ were determined on a whole-plot basis. The grain-filling period was calculated as the difference between days to maturity and days to heading.

\section{Data analysis}

The combined analyses of variance (ANOVA) for the measured traits were performed using the GENES statistical software (Cruz, 2013). The phenotypic correlation coefficient was calculated using the mean data of the measured traits over locations. The correlation coefficient and standardized regression coefficient among the dependent and independent variable were determined using the STATISTICA 7 software (StatSoft Inc., 2004).

\section{Path coefficient analyses}

The path analysis of grain yield and yield components was performed considering the 
sequential ontogenetic plant development as described by Zadoks et al. (1974) and elaborated by Kozak and Azevedo (2011).

The sequential path analysis model was determined based on the cereal growth scale described by Zadoks et al. (1974). Therefore, the yield components were classified as first, second, and third order on the path analysis model on the basis of the cereal growth scale (Zadoks et al., 1974) considering sequential yield component development because the yield components that develop in the early stage of plant development only affect the yield components that developed in the later stage but not the reverse.

The path analysis (direct effect) for each dependent variable was conducted as hierarchical (sequential) multiple regression for each variable in the path model (Figure 1). For each variable, the multiple regression was performed by taking only the variables that have a direct effect on the dependent variable. Throughout the path model, the yield components that directly influence the dependent variable were included as regressors as described by Dofing and Knight (1992) and Kozak and Azevedo (2011). The beta weight from the multiple regressions is used as path coefficient $\mathrm{P}_{\mathrm{ij}}$, where $i$ indicates the effect and $j$ indicates the cause. $\mathrm{P}^{2}{ }_{\mathrm{ij}}$ showed the proportion of the total variance that is caused by the causal variable.

The following equations are used in regression analysis to estimate the path coefficient. The equations are derived from the path model of Figure 1.

$$
\begin{aligned}
& Y=P_{Y} X_{1}+P_{Y} X_{2}+P_{Y} X_{3} \\
& X_{3}=P_{32} X_{2}+P_{31} X_{1}+P_{37} X_{7}+P_{38} X_{8} \\
& X_{2}=P_{21} X_{1}+P_{25} X_{5}+P_{27} X_{7} \\
& X_{1}=P_{14} X_{4}+P_{16} X_{6} \\
& X_{5}=P_{51} X_{1}+P_{56} X_{6} \\
& X_{7}=P_{75} X_{5}+P_{76} X_{6}+P_{78} X_{8} \\
& X_{8}=P_{85} X_{5}+P_{86} X_{6}+P_{84} X_{4} \\
& X_{6}=P_{64} X_{4}
\end{aligned}
$$

In these equations, $X_{1}$ is spike $/ \mathrm{m}^{2}, X_{2}$ is kernel number/spike, $X_{3}$ is TKW, $X_{4}$ is tillers/ spike, $X_{5}$ spikelets/spike, $X_{6}$ is days to heading, $X_{7}$ is grain-filling period, $X_{8}$ is plant height, and $Y$ is grain yield $/ \mathrm{m}^{2}$.

The indirect effect of the independent variable on the dependent variable was calculated by multiplying all path coefficients found between the independent and the dependent variable along the path model. The indirect and the total effect (direct + indirect effect) of each variable upon other variables was estimated suing path.sas code (SAS Institute Inc., 2002) developed by Wuensch (2012). 


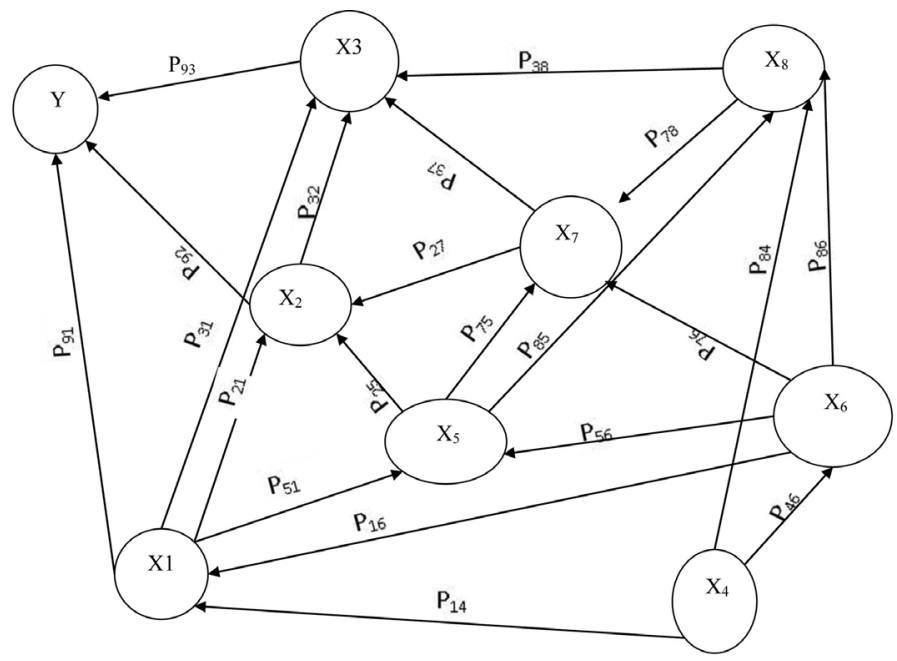

Figure 1. Path coefficient diagrams showing the inter-relationships among spike $/ \mathrm{m}^{2}\left(\mathrm{X}_{1}\right)$, kernel number/spike $\left(X_{2}\right)$, 1000-kernel weight $\left(X_{3}\right)$, tiller/spike $\left(X_{4}\right)$, spikelets/spike $\left(X_{5}\right)$, days to heading $\left(X_{6}\right)$, grain-filling period $\left(X_{7}\right)$, plant height $\left(\mathrm{X}_{8}\right)$, and grain yield $/ \mathrm{m}^{2}(\mathrm{Y})$. The single headed arrows indicate the path coefficients, and the doubleheaded arrows indicate the simple correlation coefficient.

\section{RESULTS}

ANOVA of measured traits showed significant differences among genotypes for all measured traits at $\mathrm{P}<0.01$ (Table 1). The correlation coefficient was estimated using the mean data over locations. The Pearson correlation that was estimated from the mean data of the measured traits over locations was used as the base for path analysis.

\section{Table 1. Analysis of variance for the measured agronomic traits evaluated at Ambo and Asasa.}

\begin{tabular}{lcccccccccc}
\hline Source of variation & \multicolumn{10}{c}{ Mean square } \\
\cline { 2 - 11 } & d.f. & DH & GFP & PLH & TPP & SPM2 & $\begin{array}{c}\text { Spikelets/ } \\
\text { spike }\end{array}$ & $\begin{array}{c}\text { Kernel No./ } \\
\text { spike }\end{array}$ & $\begin{array}{c}1000 \text {-grain } \\
\text { weight }\end{array}$ & $\begin{array}{c}\text { Yield/ } \\
\mathrm{m}^{2}\end{array}$ \\
\hline Location & 1 & $17596.0^{* *}$ & $5394.90^{* *}$ & $12111.0^{* *}$ & $1291.9^{* *}$ & $1022.6^{* *}$ & $5488.9^{* *}$ & $5018.1^{* *}$ & $1302.8^{* *}$ & $2859303.5^{* *}$ \\
Genotypes & 99 & $137.8^{* *}$ & $77.95^{* *}$ & $635.5^{* *}$ & $4.3^{* *}$ & $3.8^{* *}$ & $812.2^{* *}$ & $500.6^{* *}$ & $241.3^{* *}$ & $21319.4^{* *}$ \\
Location x genotype & 99 & $10.8^{* *}$ & $25.79^{*}$ & $86.1^{*}$ & $1.5^{* *}$ & $1.5^{* *}$ & $55.9^{* *}$ & $48.7^{* *}$ & $16.1^{* *}$ & $7248.9^{* *}$ \\
Error & 198 & 4.5 & 17.79 & 22.1 & 1.1 & 0.9 & 18.2 & 13.2 & 13.1 & 4196.4 \\
Coefficient of variation (\%) & & 3.2 & 10.85 & 4.94 & 23.04 & 19.3 & 10.1 & 10.1 & 10.1 & 15.1 \\
\hline
\end{tabular}

$* *$ Significant at $1 \%$ level of probability. d.f. = degrees of freedom; $\mathrm{DH}=$ days to heading; GFP = grain-filling period; PLH $=$ plant height; TPP $=$ tiller $/$ plant; $\mathrm{SPM} 2=\mathrm{spike} / \mathrm{m}^{2}$.

\section{Correlation analysis}

The correlation coefficient between grain yield $/ \mathrm{m}^{2}$ and other agronomic traits was presented in Table 2. The result showed that days to heading had a significant negative correlation with grainfilling period, TKW, and grain yield $/ \mathrm{m}^{2}$, but it has a positive correlation with plant height (Table 2). 
Grain yield $/ \mathrm{m}^{2}$ has a significant positive correlation with grain-filling period $(\mathrm{r}=0.56)$, spike $/ \mathrm{m}^{2}(\mathrm{r}=$ $0.29)$, and TKW $(r=0.49)$, which showed that these yield components positively affect grain yield in barley. In contrast, days to heading and plant height affect grain yield negatively. Among the principal yield components, spike $/ \mathrm{m}^{2}$ has a positive association with TKW and a negative association with kernel number/spike. Significant negative correlations were observed between spike $/ \mathrm{m}^{2}$ with kernel number/spike $(\mathrm{r}=-0.81)$ and TKW with kernel number/spike $(\mathrm{r}=-0.65)$.

Table 2. Pearson correlation coefficient among grain yield and yield-related traits.

\begin{tabular}{|c|c|c|c|c|c|c|c|c|c|}
\hline & DH & GFP & PLH & TPP & SPM2 & Spltsp & KNPP & TKW & GYLPm $^{2}$ \\
\hline Days to heading (DH) & 1.000 & - & & & & & & & \\
\hline Grain-filling period (GFP) & $-0.48^{* *}$ & 1.000 & & & & & & & \\
\hline Plant height (PLH) & $0.68 * *$ & $-0.56 * *$ & 1.000 & & & & & & \\
\hline Tiller/plant (TPP) & 0.034 & 0.059 & 0.099 & 1.000 & & & & & \\
\hline Spike/m² (SPM2) & -0.162 & $0.24 *$ & $-0.26^{*}$ & $0.590^{*}$ & 1.000 & & & & \\
\hline Spikelets/spike (Spltsp) & 0.076 & $-0.26 *$ & 0.150 & $-0.653 *$ & $-0.81 * *$ & 1.000 & & & \\
\hline Kernel/spike (KNPP) & 0.064 & $-0.22 *$ & 0.147 & $-0.637 *$ & $-0.81 * *$ & $0.98 * *$ & 1.000 & & \\
\hline 1000-kernel weight (TKW) & $-0.30^{* *}$ & $0.63 * *$ & $-0.38 * *$ & $0.41 * *$ & $0.46^{* *}$ & $-0.69 * *$ & $-0.65^{* *}$ & 1.00 & \\
\hline Grain yield $/ \mathrm{m}^{2}\left(\mathrm{GYLDM}^{2}\right)$ & $-0.37 * *$ & $0.56 * *$ & $-0.39 * *$ & 0.078 & $0.291 *$ & -0.028 & 0.038 & $0.49 * *$ & 1.00 \\
\hline
\end{tabular}

*significant at $5 \% ; *$ significant at $1 \%$.

\section{Path analysis of grain yield $/ \mathrm{m}^{2}$}

The path analysis of grain yield on principal yield components (spike $/ \mathrm{m}^{2}$, kernel number/spike, and TKW) showed that spike/ $\mathrm{m}^{2}$, kernel number/spike, and TKW have positive direct effects on grain yield (Table 3 ). The highest direct effect was exerted by kernel number/ spike (1.63), which was followed by spike $/ \mathrm{m}^{2}(1.14)$. The total effect of the yield components including the direct and the indirect effects via other yield components showed that kernel/ spike and TKW have a significant positive total effect on grain yield, which demonstrated that these traits can be used as selection criteria to improve grain yield in barley.

Table 3. Path coefficient analysis of grain yield $/ \mathrm{m}^{2}$ of 100 barley genotypes grown in Asasa and Ambo, Ethiopia.

\begin{tabular}{|c|c|}
\hline Pathway & Effect \\
\hline \multicolumn{2}{|c|}{ Spike $/ \mathrm{m}^{2} v s$ grain yield } \\
\hline Direct effect & 1.14 \\
\hline \multicolumn{2}{|l|}{ Indirect effect via } \\
\hline Kernel/spike & -0.02 \\
\hline Kernel weight & -0.31 \\
\hline Total effect & 0.192 \\
\hline Correlation & 0.291 \\
\hline \multicolumn{2}{|l|}{ Kernel/spike } \\
\hline Direct effect & 1.63 \\
\hline \multicolumn{2}{|l|}{ Indirect effect via } \\
\hline Spike $/ \mathrm{m}^{2}$ & - \\
\hline Kernel weight & -0.811 \\
\hline Total effect & 0.819 \\
\hline Correlation & 0.038 \\
\hline \multicolumn{2}{|l|}{ Kernel weight } \\
\hline Direct effect & 1.04 \\
\hline \multicolumn{2}{|l|}{ Indirect effect via } \\
\hline Spike $/ \mathrm{m}^{2}$ & - \\
\hline Kernel/spike & - \\
\hline Total effect & 1.04 \\
\hline Correlation & 0.495 \\
\hline $\mathrm{R}^{2}$ & 0.908 \\
\hline
\end{tabular}


The path analysis of grain yield and principal yield components showed that spike/ $\mathrm{m}^{2}$, kernel/spike, and TKW best explain the total variation of grain yield with $\mathrm{R}^{2}=0.908$ (Table 3). This indicates that the path analysis model used in this study to explain the variability of grain yield $/ \mathrm{m}^{2}$ fit well and explained the proposed hypothesis.

The analysis of indirect effects of yield components on grain yield $/ \mathrm{m}^{2}$ showed that spike/ $\mathrm{m}^{2}$ exerts a significant negative indirect effect via kernel weight (Table 3). Kernel number/spike has a strong negative effect $(-0.811)$ on grain yield via kernel weight. Even with negative indirect effects, the total effect on grain yield is positive (0.819), indicating that the net effect is positive because of the high direct effect.

\section{Path analysis of principal yield components}

In this study spike $/ \mathrm{m}^{2}$, kernel number/spike, and TKW were considered as principal yield components (Figure 1) because they affect grain yield directly in the path model. Principal yield components are defined as the yield components that affect grain yield directly or at the first order in the path model. Tiller/plant and days to heading were considered the last-order components in the path model (Figure 1). These two traits affected spike $/ \mathrm{m}^{2}$ in the path model, and tiller/plant produced a direct positive effect (0.596; Table 4). Tiller/plant has a positive direct and total effect on spike $/ \mathrm{m}^{2}$ and can be used as a selection criterion to increase the number of spike $/ \mathrm{m}^{2}$ (Table 5). The spike $/ \mathrm{m}^{2}$ has a negative direct (-0.808) and total effect $(-0.821)$ on kernel number/spike (Table 4). Spikelets/spike exerted a positive direct effect $(0.982)$ and total effect $(0.969)$ on kernel/spike. TKW was affected negatively by spike/ $\mathrm{m}^{2}$ $(-0.31)$, but it has a total positive effect $(0.376)$, which suggested that the negative direct effect is compensated by the positive indirect effect. The highest negative effect on TKW was exerted by kernel number/spike (Table 4).

\section{Path analysis among other agronomic traits}

The total (the direct + the indirect effect) and indirect effects among yield components are presented in Tables 5 and 6 , respectively. Among the yield components, the negative direct effect was exerted by days to heading on grain-filling period. The same trait exerted a positive direct effect on plant height (0.681; Table 5). Plant height also had a negative direct effect on grain-filling period.

The path analysis of secondary yield components (spikelets/spike, grain-filling period, and plant height) in the path model showed that plant height and spikelets/spike affected negatively the grain-filling period. Plant height and days to heading exerted negative direct effects on grain-filling period. This showed that these secondary yield components negatively affect grain-filling period and consequently grain yield via grain-filling period. Days to heading positively affected plant height, indicating that the long vegetative period resulted in tall plants.

The indirect effect analysis among yield components showed that days to heading had a negative indirect effect on grain-filling period via plant height (-0.284; Table 6). Tiller/plant had a significant negative effect on spikelets/spike and a positive effect on kernel number/ spike. 
Table 4. Path coefficient analysis of principal yield components (Spike $/ \mathrm{m}^{2}$, kernel number/spike ${ }^{1}$, and 1000-kernel weight) of 100 barley genotypes grown in Asasa and Ambo, Ethiopia.

\begin{tabular}{|c|c|c|c|c|c|}
\hline Trait & Effect & Trait & Effect & Trait & Effect \\
\hline $\begin{array}{l}\text { Spike/m² } \\
\text { vs tiller/spike }\end{array}$ & & $\begin{array}{l}\text { Kernel } / \text { spike } \\
v_{s} \text { spike } / \mathrm{m}^{2}\end{array}$ & & $\begin{array}{l}\text { Kernel weight } \\
v s \text { spike/ } \mathrm{m}^{2}\end{array}$ & \\
\hline Direct effect & 0.596 & Direct effect & -0.808 & Direct effect & -0.31 \\
\hline Indirect effect via & & Indirect effect via & & Indirect effect & \\
\hline Days to heading & -0.006 & Spikelets/spike & -0.80 & Kernel/spike & 0.0156 \\
\hline Total effect & 0.59 & Grain-filling period & -0.006 & Grain-filling period & -0.077 \\
\hline \multirow[t]{2}{*}{ Correlation } & 0.59 & Total effect & -0.821 & Total effect & 0.376 \\
\hline & & Correlation & -0.808 & Correlation & 0.456 \\
\hline \multicolumn{6}{|l|}{ Days to heading } \\
\hline Direct effect & -0.18 & & & & \\
\hline Indirect effect via & & $v s$ spikelets/spike & & vs Kernel/spike & \\
\hline \multirow[t]{18}{*}{ Correlation } & -0.162 & Direct effect & 0.982 & Direct effect & -0.78 \\
\hline & & Indirect effect via & & Indirect effect via & - \\
\hline & & Grain-filling period & -0.013 & Total effect & -0.78 \\
\hline & & Total effect & 0.969 & Correlation & -0.651 \\
\hline & & Correlation & 0.959 & & \\
\hline & & & & $v s$ Grain-filling period & \\
\hline & & $v s$ grain-filling period & & Direct effect & 0.482 \\
\hline & & Direct effect & 0.041 & Indirect effect via & \\
\hline & & Total effect & 0.041 & Kernel/spike & -0.032 \\
\hline & & Correlation & -0.223 & Total effect & -0.032 \\
\hline & & & & Correlation & 0.628 \\
\hline & & & & $v s$ Plant height & \\
\hline & & & & Direct effect & -0.08 \\
\hline & & & & Indirect effect via & \\
\hline & & & & Grain-filling period & -0.202 \\
\hline & & & & Total effect & -0.269 \\
\hline & & & & Correlation & -0.384 \\
\hline & 0.38 & & 0.98 & & 0.70 \\
\hline
\end{tabular}

Table 5. Total effect of grain yield-related traits on grain yield and yield components.

\begin{tabular}{lrcrrrrrr}
\hline & DH & GFP & PLH & SPPM2 & Spltsp & KNPP & TKW & Tiller/plant \\
\hline Days to heading (DH) & 0.000 & 0.000 & 0.000 & 0.000 & 0.000 & 0.000 & 0.000 & 0.034 \\
Grain-filling period (GFP) & -0.474 & 0.000 & -0.420 & 0.094 & -0.310 & 0.000 & 0.000 & 0.008 \\
Plant height (PLH) & 0.681 & 0.000 & 0.000 & 0.000 & 0.000 & 0.000 & 0.000 & 0.099 \\
Spike/m² (SPPM2) & -0.180 & 0.000 & 0.000 & 0.000 & 0.000 & 0.000 & 0.000 & 0.590 \\
Spikelets/spike (Spltsp) & 0.088 & 0.000 & 0.000 & -0.820 & 0.000 & 0.000 & 0.000 & -0.486 \\
Kernel/spike (KNPP) & 0.070 & 0.041 & -0.017 & -0.821 & 0.969 & 0.000 & 0.000 & -0.488 \\
1000-kernel weight (TKW) & -0.282 & 0.450 & -0.269 & 0.376 & -0.905 & -0.780 & 0.000 & 0.194 \\
Yield/m ${ }^{2}\left(\right.$ GYLDm $\left.^{2}\right)$ & -0.384 & 0.535 & -0.308 & 0.192 & 0.638 & 0.819 & 1.040 & 0.078 \\
\hline
\end{tabular}

Table 6. Indirect effect of grain yield-related traits on grain yield and yield components.

\begin{tabular}{lrrrrrrrr}
\hline & DH & GFP & PLH & SPPM2 & Spltsp & KNPP & TKW & Tiller/plant \\
\hline Days to heading (DH) & 0.000 & 0.000 & 0.000 & 0.000 & 0.000 & 0.000 & 0.000 & 0.000 \\
Grain-filling period (GFP) & -0.284 & 0.000 & 0.000 & 0.254 & 0.000 & 0.000 & 0.000 & 0.008 \\
Plant height (PLH) & 0.000 & 0.000 & 0.000 & 0.000 & 0.000 & 0.000 & 0.000 & 0.023 \\
Spike/m² (SPPM2) & 0.000 & 0.000 & 0.000 & 0.000 & 0.000 & 0.000 & 0.000 & -0.006 \\
Spikelets/spike (Spltsp) & 0.148 & 0.000 & 0.000 & 0.000 & 0.000 & 0.000 & 0.000 & -0.486 \\
Kernel/spike (KNPP) & 0.070 & 0.000 & -0.017 & -0.801 & -0.013 & 0.000 & 0.000 & 0.488 \\
1000-kernel weight (TKW) & -0.282 & -0.032 & -0.189 & 0.686 & -0.905 & 0.000 & 0.000 & 0.194 \\
Yield/m (GYLDm $^{2}$ ) & -0.384 & 0.535 & -0.308 & -0.948 & 0.638 & -0.811 & 0.000 & 0.078 \\
\hline
\end{tabular}




\section{DISCUSSION}

ANOVA showed the existence of ample genetic variability among the evaluated genotypes of barley that can be explored in future breeding programs to develop new cultivars that are suitable for the early production system of the country. This genetic variability is observed in all measured traits among genotypes. Setotaw et al. (2010) also reported high genetic variability among barley accessions from Ethiopia for different agronomic traits including grain yield. To explore this genetic variability, employing correlation coefficient and path analysis to understand the relationship between grain yield and yield components, will be crucial.

According to our study, grain yield was positively related to grain-filling period and spike $/ \mathrm{m}^{2}$. Positive and significant associations between grain yield $/ \mathrm{m}^{2}$ and spike $/ \mathrm{m}^{2}$ were also reported by Dofing and Knight (1992) and Deniz et al. (2009). The positive association between grain-filling period and grain yield can be explained by the observation that a long period of sink formation results in a large seed size and consequently increased grain yield. The study also indicated that the long vegetative period has a negative significant effect on grain yield because the plant requires more water to maintain it, consequently reducing the grain-filling period and exposing the plant to the terminal stress period of the season that frequently occurred during the growing season in the region. The negative association between days to heading and grain yield was also reported by Deniz et al. (2009) for barley. Our study also showed that selecting tall plants can reduce grain yield significantly because this trait caused a high lodging percent and consequently reduced kernel weight and the number of fertile spike $/ \mathrm{m}^{2}$.

Even if association studies among grain yield and yield-related traits provide some clue to explain how grain yield and other agronomic traits are interrelated, it should not be used alone as a tool for developing selection criteria because of the complex nature of the associations. Therefore, it is important to employ path analysis to understand clearly the interrelationship among yield components and grain yield. In this study, the path coefficient analysis was performed on the basis of the cereal ontogenetic plant development, as described by Zadoks et al. (1974). In plant development, only traits that develop early can affect those that develop in the later stage; the reverse is not true. The ontogenetic approach of path analysis for developing selection criteria to improve grain yield was reported by Dofing and Knight (1992) and Deniz et al. (2009) in barley, Donaldson et al. (2001) in winter wheat, Maman et al. (2004) in sorghum, and García del Moral et al. (2003) in durum wheat.

As described and elaborated by Wright (1934) and Li (1976), path analysis should be employed to test the goodness fit of the path analysis model that was developed based on past research and not to infer the best model, as it was used by Mohammadi et al. (2003) and Maleki et al. (2011). These two authors used sequential path analysis to infer the best model based on the percentage of variance that was explained by the independent variable (yield-related traits) on grain yield and not on ontogenetic plant development. In our study, the path coefficient analysis of grain yield was performed based on an ontogenetic path model and showed that spike/ $\mathrm{m}^{2}$, kernel number/spike, and kernel weight had positive direct effects on grain yield, which agreed with the result that was reported by Dofing and Knight (1992). Deniz et al. (2009) also reported that spike $/ \mathrm{m}^{2}$ had a positive direct effect on grain yield in barley. Spike $/ \mathrm{m}^{2}$ and kernel number/spike exerted negative indirect effects on grain yield via kernel weight, but their total effect (direct + indirect effect) is positive and significant, which showed that these traits can be used as selection criteria to improve grain yield in barley in an early production 
system. The path analysis based on the ontogenetic approach showed that kernel weight has a direct positive effect on grain yield but not indirect effect because kernel weight is the last trait that is developed in the late stage of plant development; this differs from the conventional path analysis method (Dewey and Lu, 1959). The study showed that spike $/ \mathrm{m}^{2}$ and TKW can be used as selection criteria because these traits have a significant positive direct effect and positive correlation with grain yield. Similar results were also reported by Dofing and Knight (1992). García del Moral et al. (2003) also reported the positive direct effect of spike $/ \mathrm{m}^{2}$ on grain yield in durum wheat that can be used as a selection criterion.

The path analysis of the principal yield components showed the positive direct effect of tiller/plant on spike $/ \mathrm{m}^{2}$. The negative direct effect and indirect effect of spike $/ \mathrm{m}^{2}$ on kernel number/spike showed the importance of balance during selection for these traits, even if spike/ $\mathrm{m}^{2}$ has a positive total effect on kernel weight, the principal yield component. To increase the kernel weight, selection can be done to favor spike $/ \mathrm{m}^{2}$ and grain-filling period by maintaining kernel number/spike at a reasonable number.

Our study showed that the ontogenetic path analysis is more efficient in determining the direct and indirect effects to develop appropriate selection criteria to improve grain yield in barley in an early production system. Spike $/ \mathrm{m}^{2}$, kernel weight, and grain-filling period can be used as selection criteria in this region to improve productivity in barley. As presented by Dofing and Knight (1992) and García del Moral et al. (2003), the ontogenetic approach to determine the path analysis model is appropriate and explains the biological system of plant growth. Even if the indirect effect estimation used here is different from that used by García del Moral et al. (2003), the hypothesis is identical. In our study, indirect effect estimation was performed by multiplying the path coefficient along the path diagram model, which was used by Deniz et al. (2009). In contrast, García del Moral et al. (2003) employed the traditional estimation method that was used by Dewey and $\mathrm{Lu}$ (1959).

This study showed that the ontogenetic path analysis model best explained grain yield in barley. In addition, this model makes the interpretation more straightforward than that of the conventional path analysis method. Developing the path model using the sequential regression analysis without considering the biological plant growth stage can produce the wrong conclusion. In our study, to improve grain yield in an early production system can be done by selecting plants of average plant height with high TKW, spike $/ \mathrm{m}^{2}$, and kernel number/spike and selecting against a long vegetative period.

\section{ACKNOWLEDGMENTS}

The authors would like use this opportunity to thank the technical staff of Kulumsa Agricultural Research Center barley breeding team for executing the field and laboratory work. The Ethiopian Agricultural Research Institute provided financial support, and ICARDA provided part of the germplasm that was used in this study. Coordenação de Aperfeiçoamento de Pessoal de Nível Superior (CAPES) for the fellowship grant to T.A. Setotaw and Empresa Brasileira de Pesquisa Agropecuária (EMBRAPA) for the financial support of the publication.

\section{REFERENCES}

Abay F and Bjørnstad A (2009). Specific adaptation of barley varieties in different locations in Ethiopia. Euphytica 167: 181-195. 
Ariyo OJ, Aken'ova ME and Fatokun CA (1987). Plant character correlations and path analysis of pod yield in Okra (Abelmoschus esculentus). Euphytica 36: 677-686.

Bhatt GM (1973). Significance of path coefficient analysis in determining the nature of character association. Euphytica 22: 338-343.

Ceccarelli S and Grando S (1991). Environment of selection and type of germplasm in barley breeding for low-yielding conditions. Euphytica 57: 207-219.

Cruz CD (2013). GENES - a software package for analysis in experimental statistics and quantitative genetics. Acta Sci. Agron. 35: 271-276.

Deniz B, Kavurmaci Z and Topal M (2009). Determination of ontogenetic selection criteria for grain yield in spring barley (Hordeum vulgare) by path-coefficient analysis. Afr. J. Biotechnol. 8: 2616-2622.

Dewey DR and Lu KH (1959). A correlation and path-coefficient analysis of components of crested wheat grass seed production. Agron. J. 51: 515-518.

Dofing SM and Knight CW (1992). Alternative model for path analysis of small-grain yield. Crop Sci. 32: 487-489.

Donaldson E, Schillinger WF and Dofing SM (2001). Straw production and grain yield relationships in winter wheat. Crop Sci. 41: 100-106.

El-Hennawy MA (1997). Genetic variability and path coefficient analysis of some agronomic characters in barley (Hordeum vulgare L.). Ann. Agric. Sci. 35: 773-783.

García del Moral LF, Rharrabti Y, Villegas D and Royo C (2003). Evaluation of grain yield and its components in durum wheat under Mediterranean conditions. Agron. J. 95: 266-274.

Johnson HW, Robinson HF and Comstock RE (1955). Genotypic and phenotypic correlations in soybean and their implications in selection. Agron. J. 47: 477-483.

Kozak M and Azevedo RA (2011). Does using stepwise variable selection to build sequential path analysis models make sense? Physiol. Plant 141: 197-200.

Lakew B, Gebre H and Alemayehu F (1996). Barley Production and Research in Ethiopia. In: Barley Research in Ethiopia: Past Work and Future Prospects (Gebre H and van Leur J, eds.). Institute of Agricultural Research, Addis Ababa, 1-8.

Li CC (1976). First Course in Population Genetics. Boxwood Press, Pacific Grove.

Maleki HH, Karimzadeh G, Darvishzadeh R and Sarrafi A (2011). Correlation and sequential path analysis of some agronomic traits in tobacco (Nicotiana tabaccum L.) to improve dry leaf yield. Aust. J. Crop Sci. 5: 1644-1648.

Maman N, Mason SC, Lyon DJ and Dhungana P (2004). Yield components of pearl millet and grain sorghum across environments in the Central Great Plains. Crop Sci. 44: 2138-2145.

Mandal N and Dana I (1993). Correlation and path-coefficient analysis in two-rowed barley (Hordeum distichum L.). Environ. Ecol. 11: 233-234.

Mohammadi SA, Prasanna BM and Singh NN (2003). Sequential path model for determining interrelationships among grain yield and related characters in maize. Crop Sci. 43: 1690-1697.

Naik VR, Hanchinal RR, Maled BG and Patil BN (1998). Correlation and path analysis in barley. Karnataka J. Agric. Sci. 11: 230-232.

Sajeda B, Firoza K, Begum S and Khatun F (1997). Genetic parameters and character association in exotic genotypes of two rowed barley. Bangladesh J. Bot. 26: 121-126.

SAS Institute Inc. (2002). SAS Proprietary Software Version 9. SAS Inst. Inc., Cary.

Setotaw TA, Dias LAS and Missio RF (2010). Genetic divergence among barley accessions from Ethiopia. Crop Breed. Appl. Biot. 10: 116-123.

Shami I, Bhutta WM and Khaliq R (1997). Path-coefficient analysis of some quantitative characters in husked barley. Pak. J. Agri. Sci. 34: 108-110.

Singh AK, Singh SB and Yasava HS (1998). Correlation and path analysis in early generation. Ann. Agr. Res. 19: 260-264.

Smith ME, Coffman WR and Barker TC (1990). Environmental Effects on Selection Under High and Low Input Conditions. In: Genotype-by-Environment Interaction and Plant Breeding (Kang MS, ed.). Department of Agronomy, Louisiana Agriculture Experimental Station, Baton Rouge, 261-272.

StatSoft Inc. (2004). STATISTICA (data analysis software system), version 7. Available at [http://www.statsoft.com]. Accessed August 13, 2007.

Wright S (1934). The method of path coefficients. Ann. Math. Stat. 5: 161-215.

Wuensch KL (2012). An Introduction to Path Analysis. Available at [http://core.ecu.edu/psyc/wuenschk/MV/SEM/Path. pdf]. Accessed January 15, 2013.

Zadoks JC, Chang TT and Konzak CF (1974). A decimal code for growth stages of cereals. Weed Res. 14: 415-421.

Genetics and Molecular Research 13 (2): 4635-4646 (2014) 